\title{
Dorsal Hippocampal Actin Polymerization Is Necessary for Activation of G-Protein-Coupled Estrogen Receptor (GPER) to Increase CA1 Dendritic Spine Density and Enhance Memory Consolidation
}

\author{
미aekyoon Kim, Jayson C. Schalk, Wendy A. Koss, Rachel L. Gremminger, OLisa R. Taxier, Kellie S. Gross, \\ and $\odot$ Karyn M. Frick \\ Department of Psychology, University of Wisconsin-Milwaukee, Milwaukee, Wisconsin 53211
}

Activation of the membrane estrogen receptor G-protein-coupled estrogen receptor (GPER) in ovariectomized mice via the GPER agonist G-1 mimics the beneficial effects of $17 \beta$-estradiol $\left(\mathrm{E}_{2}\right)$ on hippocampal CA1 spine density and memory consolidation, yet the cellsignaling mechanisms mediating these effects remain unclear. The present study examined the role of actin polymerization and c-Jun $\mathrm{N}$-terminal kinase (JNK) phosphorylation in mediating effects of dorsal hippocampally infused G-1 on CA1 dendritic spine density and consolidation of object recognition and spatial memories in ovariectomized mice. We first showed that object learning increased apical CA1 spine density in the dorsal hippocampus (DH) within $40 \mathrm{~min}$. We then found that DH infusion of G-1 increased both CA1 spine density and phosphorylation of the actin polymerization regulator cofilin, suggesting that activation of GPER may increase spine morphogenesis through actin polymerization. As with memory consolidation in our previous work (Kim et al., 2016), effects of G-1 on CA1 spine density and cofilin phosphorylation depended on JNK phosphorylation in the DH. Also consistent with our previous findings, $\mathrm{E}_{2}$-induced cofilin phosphorylation was not dependent on GPER activation. Finally, we found that infusion of the actin polymerization inhibitor, latrunculin A, into the DH prevented G-1 from increasing apical CA1 spine density and enhancing both object recognition and spatial memory consolidation. Collectively, these data demonstrate that GPER-mediated hippocampal spinogenesis and memory consolidation depend on JNK and cofilin signaling, supporting a critical role for actin polymerization in the GPER-induced regulation of hippocampal function in female mice.

Key words: actin polymerization; cofilin; GPER; hippocampus; object recognition; spatial memory

Significance Statement

Emerging evidence suggests that G-protein-coupled estrogen receptor (GPER) activation mimics effects of $17 \beta$-estradiol on hippocampal memory consolidation. Unlike canonical estrogen receptors, GPER activation is associated with reduced cancer cell proliferation; thus, understanding the molecular mechanisms through which GPER regulates hippocampal function may provide new avenues for the development of drugs that provide the cognitive benefits of estrogens without harmful side effects. Here, we demonstrate that GPER increases CA1 dendritic spine density and hippocampal memory consolidation in a manner dependent on actin polymerization and c-Jun N-terminal kinase phosphorylation. These findings provide novel insights into the role of GPER in mediating hippocampal morphology and memory consolidation, and may suggest first steps toward new therapeutics that more safely and effectively reduce memory decline in menopausal women.

\section{Introduction}

Dendritic spines are essential for synaptic plasticity and memory formation (Moser et al., 1994; Knafo et al., 2001; Nimchinsky et al., 2002). Synapse loss is highly correlated with cognitive dysfunction in Alzheimer's disease (DeKosky and Scheff, 1990; Terry et al., 1991), a condition for which estrogen loss at menopause 
confers significantly greater risk to women. Although the potent estrogen $17 \beta$-estradiol $\left(\mathrm{E}_{2}\right)$ has long been known to regulate dendritic spine density in the CA1 region of the hippocampus (Woolley et al., 1990; Woolley and McEwen, 1992), the molecular mechanisms mediating these effects are not well understood. $\mathrm{E}_{2}$ induced CA1 spine density is associated with enhanced synaptic plasticity and memory formation (Mukai et al., 2007; Inagaki et al., 2012; McClure et al., 2013; Phan et al., 2015) and changes in ovariectomized (OVXed) rats within $40 \mathrm{~min}$ of systemic or dorsal hippocampal treatment (Phan et al., 2011; Inagaki et al., 2012; Tuscher et al., 2016), suggesting that rapid molecular events underlie $\mathrm{E}_{2}$ 's effects on spines and memory. Indeed, rapid activation of dorsal hippocampal extracellular signal-regulated kinase (ERK) cell signaling is necessary for $\mathrm{E}_{2}$ to increase CA1 spine density (Tuscher et al., 2016), and enhance object recognition and spatial memory consolidation (Fernandez et al., 2008; Fan et al., 2010; Fortress et al., 2013b) in OVXed mice, suggesting that $E_{2}$ may use common molecular mechanisms to mediate spinogenesis and memory consolidation.

$\mathrm{E}_{2}$ may influence memory and spine morphology by binding to estrogen receptors, including G-protein-coupled estrogen receptor (GPER). Like $\mathrm{E}_{2}$, systemic dorsal hippocampal administration of the GPER agonist G-1, 1-[4-(6-bromobenzo[1,3]dioxol-5yl)-3a,4,5, 9b-tetrahydro- ${ }^{3} \mathrm{H}$-cyclopenta[c] quinolin-8-yl]-ethanone (Sandia Biotech), facilitates the acquisition and consolidation of spatial and object recognition memories in OVXed rodents (Hammond and Gibbs, 2011; Gabor et al., 2015; Kim et al., 2016; Lymer et al., 2017; Paletta et al., 2018). However, the ability of hippocampally infused G-1 to enhance object recognition and spatial memory consolidation depends on phosphorylation of c-Jun N-terminal kinase (JNK), not ERK (Kim et al., 2016), suggesting that GPER and $\mathrm{E}_{2}$ use different cell-signaling mechanisms to regulate memory formation. Yet the importance of JNK in regulating effects of GPER on CA1 dendritic spine density in vivo is unknown.

The actin cytoskeleton is a fundamental regulator of spine morphology (Penzes and Cahill, 2012). In hippocampal synapses, formation of the actin structure underlying the generation and enlargement of dendritic spines occurs within seconds of LTP induction, suggesting that synaptic plasticity is regulated by actin organization (Honkura et al., 2008). Interestingly, $E_{2}$ promotes hippocampal LTP in vitro by regulating actin polymerization (Kramár et al., 2009). The actin-binding protein cofilin is a key regulator of actin polymerization, and its inactivation via phosphorylation by signaling kinases is necessary to increase spine volume and facilitate LTP maintenance (Chen et al., 2007; Babayan and Kramár, 2013). Although cofilin inactivation is important for $\mathrm{E}_{2}$-induced hippocampal spine formation in vitro (Yuen et al., 2011; Briz and Baudry, 2014), cofilin's role in mediating effects of $\mathrm{E}_{2}$ or GPER on CA1 spine remodeling in vivo is unclear. Given the close association between synapse loss and cognitive dysfunction in Alzheimer's disease, this information could inform novel treatments for arresting synapse loss and memory decline in menopausal women.

Here, we examined the involvement of JNK and actin polymerization in the effects of GPER on CA1 spine density and memory consolidation. Dorsal hippocampus (DH) GPER activation

\footnotetext{
Milwaukee College of Letters \& Science. We thank Miranda Schwabe and Dr. Ashley Fortress for helpful insights and comments on an earlier version of this manuscript; and Dr. James R. Moyer, 3rd for use of his Olympus BX51WI microscope and NeuroLucida software.

The authors declare no competing financial interests.

Correspondence should be addressed to Karyn M. Frick at frickk@uwm.edu.

https://doi.org/10.1523/JNEUROSCI.2687-18.2019

Copyright $\odot 2019$ the authors
}

rapidly increased CA1 spine density in a manner dependent on JNK. In contrast, $\mathrm{E}_{2}$ 's ability to increase $\mathrm{CA} 1$ spinogenesis did not depend on GPER activation, which is consistent with our previous behavioral findings (Kim et al., 2016). Latrunculin A, a natural toxin that inhibits actin polymerization, prevented GPER activation from facilitating CA1 spine density and memory consolidation, suggesting that GPER's effects depend on actin rearrangement. These data demonstrate a key role for actin polymerization in GPER-induced hippocampal spinogenesis and memory consolidation, and provide additional evidence that the signaling mechanisms through which GPER regulates hippocampal function are independent from those of $\mathrm{E}_{2}$.

\section{Materials and Methods}

Subjects. All studies used 8- to 12 week-old female C57BL/6 mice from Taconic Biosciences. After surgery, mice were housed singly in a room with a $12 \mathrm{~h}$ light/dark cycle, with all procedures performed between 9:00 A.M. and 6:00 P.M. Mice had ad libitum access to food and water. All procedures were approved by the University of Wisconsin-Milwaukee Institutional Animal Care and Use Committee, and followed policies set forth by the National Institutes of Health Guide for the Care and Use of Laboratory Animals.

Surgery. Four days after arrival, mice were bilaterally OVXed and implanted with chronic indwelling guide cannulae into the DH as described previously (Boulware et al., 2013; Fortress et al., 2014; Kim et al., 2016). Mice were secured in a stereotaxic apparatus (Kopf Instruments) and anesthetized with isoflurane gas (5\% isoflurane for induction, $2 \%$ isoflurane for maintenance) in oxygen via a mask attached to the stereotax. Immediately following ovariectomy, guide cannulae (C232G; 22 gauge, Plastics One) were aimed at the $\mathrm{DH}(-1.7 \mathrm{~mm} \mathrm{AP}, \pm 1.5 \mathrm{~mm} \mathrm{ML},-2.3$ $\mathrm{mm} \mathrm{DV}$ ) or both the $\mathrm{DH}$ and dorsal third ventricle (intracerebroventricular [ICV]; $-0.9 \mathrm{~mm}$ AP, $\pm 0.0 \mathrm{~mm} \mathrm{ML},-2.3 \mathrm{~mm}$ DV). Dummy cannulae (C232DC, Plastics One) were inserted into guide cannulae to maintain patency of the cannulae. Dental cement (Darby Dental) was used to secure the guide cannulae to the skull and close the wound. Cannula placements were examined to ensure correct placement in Golgi-stained tissue (Fig. 1) or verified visually at the time of dissection for tissue taken for Western blots. Mice were given $6 \mathrm{~d}$ to recover before the start of behavioral testing and drug infusion.

Drugs and infusions. During infusions, mice were gently restrained while dummy cannulae were replaced with infusion cannulae (C3131; DH: 28 gauge, extending $0.8 \mathrm{~mm}$ beyond the $1.5 \mathrm{~mm}$ guide; ICV: 28 gauge, extending $1.0 \mathrm{~mm}$ beyond the $1.8 \mathrm{~mm}$ guide, Plastics One) attached to PE50 polyethylene tubing mounted on a $10 \mu$ l Hamilton syringe. Infusions were controlled by a microinfusion pump (KDS Legato $180, \mathrm{KD} \mathrm{Scientific)}$ at a rate of $0.5 \mu \mathrm{l} / \mathrm{min}$ in the $\mathrm{DH}$ or $1 \mu \mathrm{l} / 2 \mathrm{~min}$ into the dorsal third ventricle using an infusion cannula as described previously (Boulware et al., 2013; Fortress et al., 2014; Kim et al., 2016). Infusion cannulae remained in place for $1 \mathrm{~min}$ to allow for tissue diffusion and prevent backflow through the cannula track. For triple infusion studies in which the GPER agonist G-1 was infused bilaterally into the DH in combination with infusion of a cell-signaling or actin polymerization inhibitor ICV, the inhibitor or vehicle was infused into the DH first, followed immediately by ICV infusion of G-1 or vehicle. By infusing G-1 adjacent to the $\mathrm{DH}$ while directly inhibiting events within the $\mathrm{DH}$, this triple infusion procedure prevented tissue damage to the $\mathrm{DH}$ from two $\mathrm{DH}$ infusions in rapid succession (Fernandez et al., 2008; Zhao et al., 2010; Boulware et al., 2013; Fortress et al., 2013b; Kim et al., 2016; Tuscher et al., 2016).

G-1 and G-15 ((3aS*,4R*,9bR $\left.\mathrm{R}^{\star}\right)$-4-(6-bromo-1,3-benzodioxol-5-yl)$3 \mathrm{a}, 4,5,9 \mathrm{~b}-{ }^{3} \mathrm{H}$-cyclopenta[c] quinoline (Sandia Biotech)) are a selective GPER agonist and antagonist, respectively, at concentrations of up to 10 $\mu \mathrm{M}$ in vitro (Bologa et al., 2006; Blasko et al., 2009; Dennis et al., 2009). G-1 was dissolved in $16 \%$ DMSO in $0.9 \%$ saline and infused at a dose of $4 \mathrm{ng} /$ hemisphere into the DH or $8 \mathrm{ng}$ ICV (Kim et al., 2016). The vehicle control for G- 1 was $16 \%$ DMSO in $0.9 \%$ saline. G-15 was dissolved in $2 \%$ DMSO and infused at a dose of $1.85 \mathrm{ng} /$ hemisphere into the DH (Kim et al., 2016). The vehicle control for G-15 was $2 \%$ DMSO in $0.9 \%$ saline. 


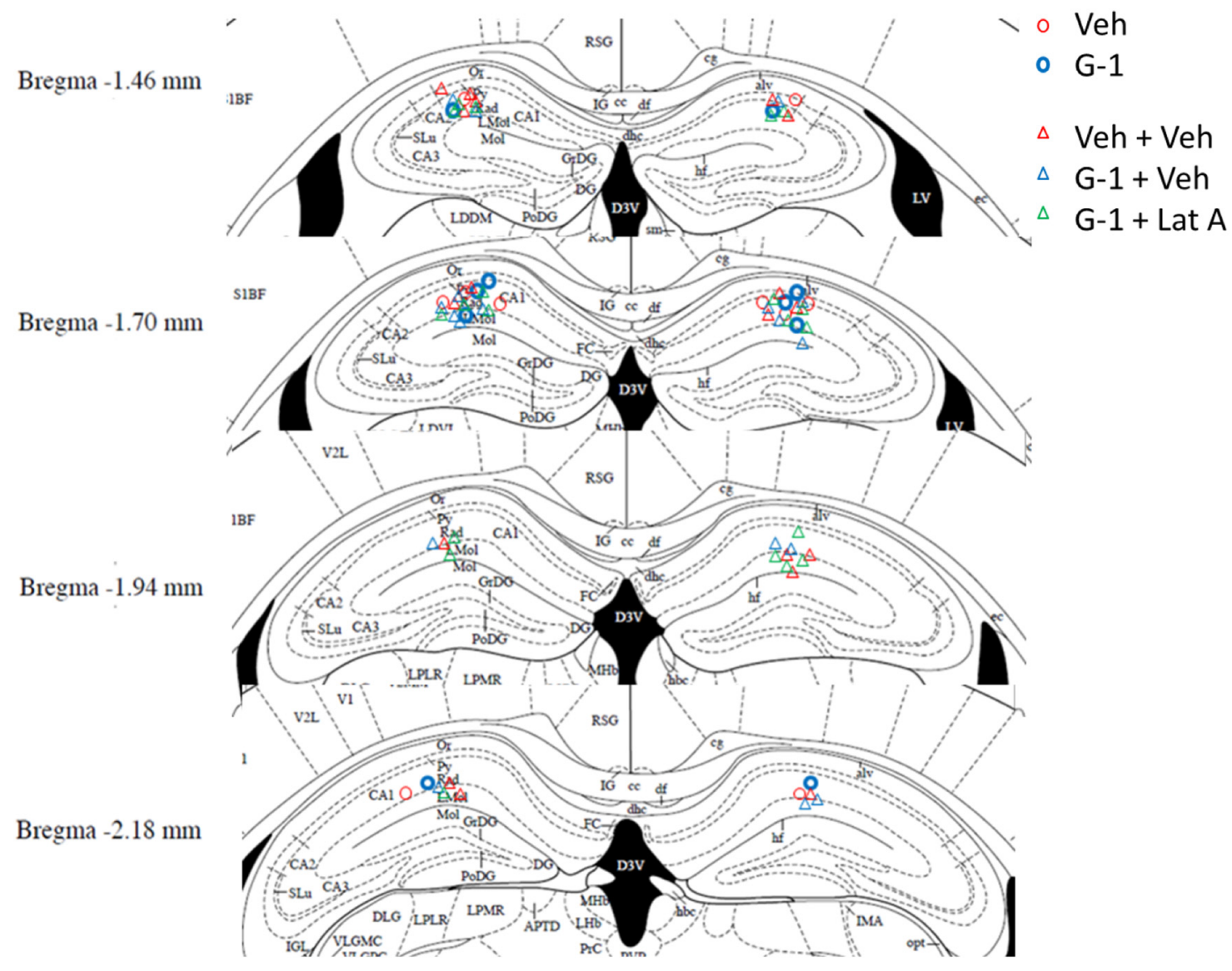

Figure 1. Schematic illustrations of dorsal hippocampal cannula placements for mice whose brains were Golgi stained. Each circle or triangle represents the approximate cannula tip placements. The position of each section relative to bregma is indicated to the left of each coronal section. Veh, Vehicle; Lat A, latrunculin A.

The JNK inhibitor SP600125 (anthra[1,9-cd]pyrazol-6(2H)-one, SigmaAldrich) was dissolved in $2 \%$ DMSO and infused at a dose of $2.75 \mathrm{ng} /$ hemisphere into the $\mathrm{DH}$ (Kim et al., 2016). Cyclodextrin-encapsulated $\mathrm{E}_{2}$ (Sigma-Aldrich) is water-soluble and is metabolized within $24 \mathrm{~h}$ (Pitha and Pitha, 1985; Pitha et al., 1986). $\mathrm{E}_{2}$ was dissolved in $0.9 \%$ saline and infused at doses of $5 \mu \mathrm{g} /$ hemisphere into the DH or $10 \mu \mathrm{g}$ ICV as in previous studies (Fernandez et al., 2008; Boulware et al., 2013; Kim et al., 2016). The vehicle control for $\mathrm{E}_{2}$ was 2-hydroxypropyl- $\beta$-cyclodextrin (Sigma-Aldrich) dissolved in $0.9 \%$ saline. Latrunculin A (Enzo Life Sciences) is a natural toxin purified from the red sea sponge Latrunculia magnifica that binds the ATP binding site of G-actin to prevent de novo actin polymerization and promote filament disassembly (Yarmola et al., 2000; Penzes and Cahill, 2012). Latrunculin A was dissolved in 1\% DMSO in saline and infused into the $\mathrm{DH}$ at doses of 10 or $50 \mathrm{ng} / \mathrm{hemi}$ sphere based on previous studies (Nelson et al., 2012; Young et al., 2014). The vehicle control was $1 \%$ DMSO dissolved in saline.

Tissue preparation and Golgi staining. Forty minutes after drug infusion, mice were cervically dislocated and decapitated, and the whole brain removed on ice. This time point was selected based on previous findings showing increased CA1 dendritic spine density 40 min after systemic G-1 treatment (Gabor et al., 2015), which was within the $30 \mathrm{~min}$ to $2 \mathrm{~h}$ time window in which $\mathrm{DH} \mathrm{E}_{2}$ infusion increases CA1 dendritic spine density (Tuscher et al., 2016). Rapid Golgi Stain Kit (FD NeuroTechnologies) was used for Golgi staining as described previously (Tuscher et al., 2016). Brain tissue was immersed in the impregnation solution at room temperature in the dark for 2 weeks. After the completion of impregnation, tissue was sliced into $100-\mu \mathrm{m}$-thick sections using a cryostat at $-30^{\circ} \mathrm{C}$, and mounted on gelatin-coated microscope slides. The sections were stained per the manufacturer's instructions and coverslipped with Permount solution. Golgi-stained sections were covered by foil when not being analyzed to protect them from light exposure.
Dendritic spine counting. Dendritic spines were counted under an Olympus BX51WI microscope $(100 \times$ with oil) using the software program NeuroLucida (Microbrightfield, version 11.08; RRID:SCR_001775). Tertiary apical dendrites were selected from pyramidal neurons in the CA1 region of the hippocampus, based on previously established studies (Frankfurt et al., 2011; Tuscher et al., 2016). The selected dendrites were limited to those 10 - to $20-\mu \mathrm{m}$-long and 0.5 - to $1.3-\mu \mathrm{m}$-thick, were well impregnated, and whose dendrites were continuous and clearly distinguishable from adjacent cells. In brains with cannula tracks, sections selected for analysis were an average of $200 \mu \mathrm{m}$ (range $=0-400 \mu \mathrm{m}$ anterior and $0-500 \mu \mathrm{m}$ posterior) from a track and neurons selected for analysis were an average distance of $823 \mu \mathrm{m}($ range $=517-1167 \mu \mathrm{m})$ from a track. At least six neurons per brain were analyzed and 2 or 3 dendrites were analyzed per neuron. Thus, a total of at least 12 segments per brain were counted. Spine density was calculated as the number of spines/10 $\mu \mathrm{m}$ dendrite. Dendritic spines were classified as one of four shape-based categories: branched, mushroom, thin, or stubby (Harris et al., 1992). Branched spines had multiple spine heads connected to a single spine neck. Mushroom spines had a head diameter that was at least twice as large as the neck diameter. Thin spines had a neck length that was at least twice as large as the neck diameter or larger. For thin spines, the head diameter was less than or equal to the neck diameter. Stubby spines did not have a discernible spine head. For stubby spines, the neck diameter was approximately equal to the total length of the spine.

Western blotting. Five, 15, or $30 \mathrm{~min}$ after infusion, mice were cervically dislocated and decapitated, and the DH dissected bilaterally on ice for Western blot analysis. Western blotting was performed as described previously (Kim et al., 2016). DH tissue was resuspended at $50 \mu \mathrm{l} / \mathrm{mg}$ in lysis buffer and homogenized by sonication (Branson Sonifier 250). Homogenates were then electrophoresed on $10 \%$ Tris- $\mathrm{HCl}$ precast gels (Bio-Rad Laboratories) and transferred to a nitrocellulose membrane. Blots were 
blocked with $5 \%$ skim milk and incubated with anti-phospho-cofilin (1:1000; Cell Signaling Technology, catalog \#3313; RRID:AB_2080597) and total cofilin (1:1000; Cell Signaling Technology, catalog \#3318; RRID: AB_10693596) primary antibody with the appropriate HRP-conjugated secondary antibody (1:5000; Cell Signaling Technology; catalog \#7074, RRID: AB_2099233). A ChemiDoc MP gel imager (Bio-Rad Laboratories) and Image Lab software (Bio-Rad Laboratories, Image Lab version 5.2; RRID: SCR_014210) were used to perform densitometry for normalization of phospho-cofilin to total cofilin.

Object recognition $(\mathrm{OR})$ and object placement $(\mathrm{OP})$. $\mathrm{OR}$ and $\mathrm{OP}$ were used to test object recognition and spatial memory consolidation, respectively. Both tasks were performed as described previously (Fernandez et al., 2008; Boulware et al., 2013; Kim et al., 2016). Experimenters conducting behavioral testing were blind to treatment status, and the order of $O R$ and OP testing was counterbalanced to minimize order effects resulting from learning, stress, or the infusion protocol. Handling, habituation, and training for both tasks were identical. Before the beginning of behavioral training, mice were handled $(30 \mathrm{~s} / \mathrm{d})$ for $3 \mathrm{~d}$ to habituate them to the experimenters. On the second day of handling, mice were familiarized to objects by placing a small Lego in their home cage; this Lego was removed just before the start of training. Mice were then habituated in an empty white arena (width, $60 \mathrm{~cm}$; length, $60 \mathrm{~cm}$; height, $47 \mathrm{~cm}$ ) for $5 \mathrm{~min} / \mathrm{d}$ for $2 \mathrm{~d}$. On the training day for each task, two identical objects were placed near the upper right and left corners of the arena. Mice remained in the arena until they had accumulated a total of $30 \mathrm{~s}$ exploring the objects. Immediately after training, mice were removed from the arena and infused. During testing, one familiar object was replaced by a novel object (OR) or was moved to a new location in the testing arena (OP). For OR, a $24 \mathrm{~h}$ delay was used to test the memory-impairing effects of latrunculin A and a 48 h delay was used to test the memory-enhancing effects of G-1 because young vehicle-infused OVXed mice remember the training objects after $24 \mathrm{~h}$, but not $48 \mathrm{~h}$ (Fernandez et al., 2008; Boulware et al., 2013; Kim et al., 2016). For OP, we used a 4 h delay to test the memory impairing effects of latrunculin A and the $24 \mathrm{~h}$ delay to test memory enhancing effects of G-1, based on previous studies showing that vehicle-infused OVXed mice remember object locations after $4 \mathrm{~h}$, but not $24 \mathrm{~h}$ (Fernandez et al., 2008; Boulware et al., 2013; Kim et al., 2016). Two weeks elapsed between behavioral tests to allow for any acute effects of drug infusion to dissipate before the next infusion. Different objects were used for OP and OR. For both tasks, time spent with the objects and elapsed time to accumulate $30 \mathrm{~s}$ of exploration were recorded using ANY-maze tracking software (ANY-maze, RRID:SCR_014289).

\section{Experimental design and statistical analysis}

Experiment 1. Experiment 1 examined whether object training itself regulates spine density in the CA1 region of the hippocampus among OVXed mice. One week after surgery, mice underwent habituation and object training with two identical objects, followed $40 \mathrm{~min}$ later by brain tissue collection for Golgi staining. Mice trained with objects $(n=9)$ were compared with home cage controls $(n=8)$ and yoked controls $(n=$ 11). Yoked control mice performed the same habituation described above for object trained mice but were not presented with objects during the training phase. These mice remained in the empty arena for the average duration as trained mice $(8 \mathrm{~min})$. Home cage controls remained in their home cages for the duration of the study. Object-trained and yoked control mice were killed $40 \mathrm{~min}$ after removal from the arena to examine learning-induced changes in CA1 apical spine density.

Experiments $2 a$ and $2 b$. Experiment 2a tested effects of DH G-1 infusion on dendritic spine density and cofilin phosphorylation. This experiment required three sets of OVXed mice. The first received vehicle $(n=$ $5)$ or G-1 $(n=5)$ infusion, and their brain tissue was collected $40 \mathrm{~min}$ later for spine analysis as described above. The second set of mice received object training and then vehicle $(n=12)$ or G-1 $(n=11)$ was infused into DH right after the training. Forty minutes later, the brains were collected for spine analysis. The third set of mice was killed 5 ( $n=$ $5), 15(n=5)$, or $30 \min (n=5)$ after G-1 infusion and were compared with vehicle-infused mice $(n=5)$ killed at each time point. The DH was dissected immediately for Western blot analysis of cofilin phosphorylation. Experiment $2 \mathrm{~b}$ examined whether GPER activation or JNK cell signaling is important for the G-1-induced alterations in cofilin phosphorylation and CA1 spine density observed in Experiment 1a. The GPER antagonist G-15 was used to ensure that G-1 effects depended on GPER activation, and the JNK inhibitor SP600125 was used to examine whether these effects also depended on JNK signaling. A new set of mice was OVXed, implanted with ICV and DH guide cannulae, and after recovery, received ICV and DH infusions, respectively, of vehicle + vehicle $(n=11), \mathrm{G}-1+$ vehicle $(n=11), \mathrm{G}-1+\mathrm{G}-15(n=10)$, or G-1 + SP600125 $(n=11)$. Brain tissue was collected and processed for spine analysis $40 \mathrm{~min}$ later. Other mice were infused with vehicle + vehicle $(n=6), \mathrm{G}-1+$ vehicle $(n=5), \mathrm{G}-1+\mathrm{G}-15(n=6)$ or vehicle + vehicle $(n=8), \mathrm{G}-1+$ vehicle $(n=7), \mathrm{G}-1+\operatorname{SP} 600125(n=7)$, and DH tissue was collected $5 \mathrm{~min}$ later for Western blot analysis of cofilin phosphorylation.

Experiment 3. This experiment tested the effects of $\mathrm{E}_{2}$ on cofilin phosphorylation and determined whether $\mathrm{E}_{2}$-induced cofilin phosphorylation depends on GPER activation. To establish effects of $E_{2}$ on cofilin phosphorylation, OVXed mice were killed $5(n=6), 15(n=6)$, or 30 $\min (n=6)$ after $\mathrm{E}_{2}$ infusion and compared with vehicle-infused mice killed at each time point $(n=6)$. DH tissue was collected for Western blot analysis of cofilin phosphorylation. To determine whether GPER activation is required for $\mathrm{E}_{2}$ to regulate cofilin phosphorylation, another set of OVXed mice was infused with vehicle + vehicle $(n=7), \mathrm{E}_{2}+$ vehicle $(n=7)$, or $\mathrm{E}_{2}+\mathrm{G}-15(n=6)$, and the $\mathrm{DH}$ was dissected 5 min later for Western blot analysis of cofilin phosphorylation.

Experiments $4 a$ and $4 b$. Experiment $4 \mathrm{a}$ examined the extent to which inhibition of actin polymerization impairs hippocampal memory consolidation. As described above, mice were OVXed and implanted with bilateral DH cannulae, trained in OR and OP, and then bilaterally infused immediately after training with vehicle (OP, $n=7$; OR, $n=9$ ) or one of two doses of latruculin A: $10 \mathrm{ng} /$ hemisphere (OP, $n=7 ; \mathrm{OR}, n=10$ ) or $50 \mathrm{ng} /$ hemisphere (OP, $n=8$; OR, $n=11$ ). Experiment $4 \mathrm{~b}$ examined whether actin polymerization is crucial for GPER-mediated CA1 spine density alterations and memory enhancement. A behaviorally subeffective dose of latrunculin A that had no effect on OR or OP on its own was used in this experiment to ensure that any effects in combination with G-1 were due to an interaction between the two compounds (Fernandez et al., 2008; Boulware et al., 2013; Fortress et al., 2013b; Kim et al., 2016). As described above, mice were OVXed and implanted with DH and ICV cannulae, and then trained in OR and OP after recovery. Immediately after training, mice received ICV and DH infusions, respectively, of vehicle + vehicle (OP, $n=11$; OR, $n=11), \mathrm{G}-1+$ vehicle $(\mathrm{OP}, n=12$; OR, $n=10)$, or G-1 + latrunculin A (OP, $n=11$; OR, $n=9)$. OR and OP retention was tested 48 and $24 \mathrm{~h}$ later, respectively. Two weeks later, mice were infused with vehicle + vehicle $(n=9)$, G- $1+$ vehicle $(n=10)$, or G-1 + latrunculin A $(n=10)$, and then cervically dislocated and decapitated 40 min later. Whole brains were collected, and Golgi impregnated as described above.

Statistical analysis. Statistical analyses were conducted using GraphPad Prism 6 software (RRID:SCR_002798). Dendritic spine and Western blot data in all studies were analyzed with one-way ANOVA followed by Fisher's LSD post hoc tests or a priori $t$ tests to examine treatment effects and between-group differences. For the OR and OP tasks, treatment differences among groups were assessed using one-way ANOVAs followed by Fisher's LSD post hoc tests. One-sample $t$ tests were also used to determine whether the time spent with each object significantly differed from chance $(15 \mathrm{~s})$, which demonstrates evidence of learning within a treatment group. Statistical significance was determined as $p \leq 0.05$ for all tests, except for a priori $t$ tests, whose significance was set at a Bonferroni-corrected $p<0.0167$.

\section{Results}

\section{Dendritic spine density in the hippocampus is altered by object training}

Previous results from our laboratory showed that $\mathrm{DH}$ infusion of $\mathrm{E}_{2}$ rapidly increases $\mathrm{CA} 1$ dendritic spine density via the same cell-signaling pathways critical for $\mathrm{E}_{2}$ to enhance object memory consolidation (Tuscher et al., 2016), suggesting that object train- 
A

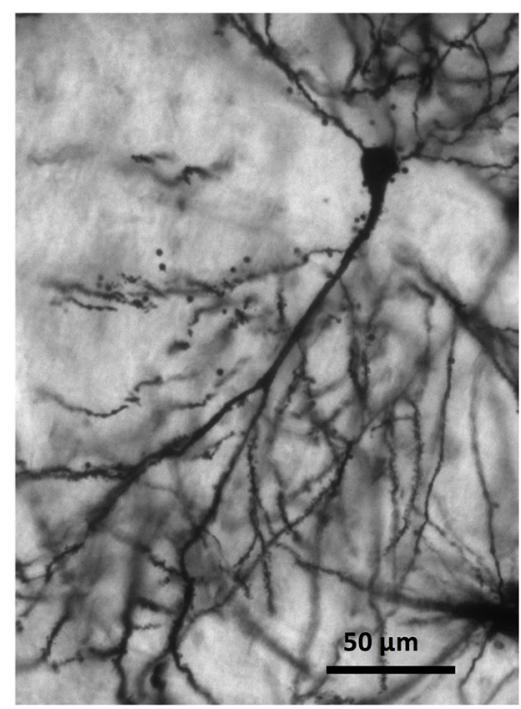

B

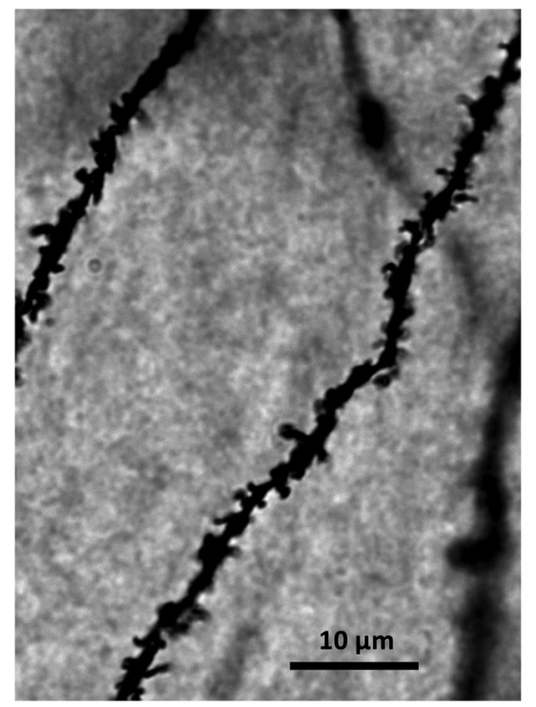

C

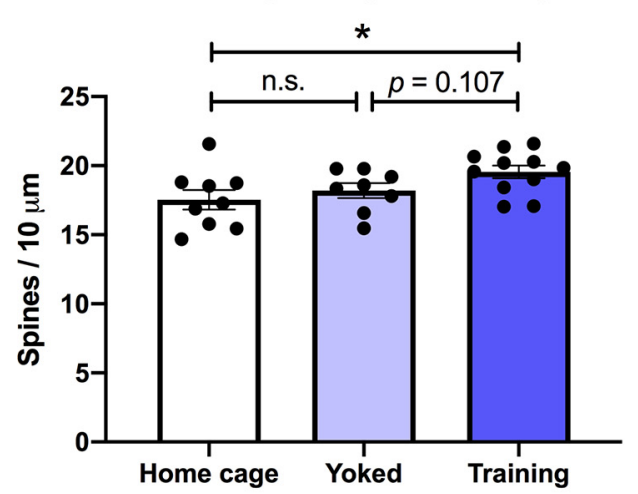

Figure 2. Learning-induced changes in CA1 dendritic spine density. $\boldsymbol{A}, \boldsymbol{B}$, Photomicrograph of Golgi-impregnated CA1 pyramidal cells at $20 \times(\boldsymbol{A})$ and $100 \times(\boldsymbol{B})$ under oil. $\boldsymbol{C}$, Forty minutes after training, CA1 apical spine density was significantly increased in the object training group only, suggesting that the increased CA1 apical spine density is induced by object training. Error bars indicate mean \pm SEM. ${ }^{*} p<0.05$, relative to home cage control. n.s. $=$ not significant.

ing itself might regulate dendritic spine density. Therefore, we first sought to determine whether object training influences CA1 dendritic spine density in OVXed mice. Representative Golgistained CA1 pyramidal neurons are illustrated in Figure $2 A, B$. As illustrated in Figure $2 C$, the density of apical spines on CA1 tertiary dendrites in object trained mice was significantly higher than that of home cage controls; this finding was supported by a significant main effect of training $\left(F_{(2,25)}=3.507, p=0.0454\right)$ and group difference $(p=0.016)$ between the object training and home cage groups. Spine density in the yoked control group was not statistically different from either the home cage $(p=0.439)$ or training $(p=0.107)$ groups.

\section{GPER activation regulates CA1 dendritic spine density and hippocampal cofilin phosphorylation in a JNK-dependent manner}

We next examined the effects of G-1 infusion on CA1 dendritic spine density. Analysis of Golgi-stained tissue revealed that DH infusion of G-1 significantly increased total CA1 apical spine density relative to vehicle $40 \mathrm{~min}$ after infusion $\left(t_{(8)}=3.056, p=\right.$ 0.0157 ; Fig. $3 A$ ). To determine the effects of $G-1$ on specific spine types, we recounted the same dendritic segments and categorized spines as thin, stubby, mushroom, or branched as described previously (Harris et al., 1992). A two-way ANOVA (spine type $\times$ treatment) revealed significant main effects of treatment $\left(F_{(1,30)}=\right.$ 9.348, $p=0.0047$; Fig. $3 B)$ and spine type $\left(F_{(4,30)}=415.9, p<\right.$ $0.0001)$, and a significant interaction $\left(F_{(4,30)}=4.298, p=\right.$ 0.0072 ). As before, total spine number was increased by G-1 (Fig. $3 B ; p=0.0018)$. However, this effect was driven by a selective effect of G-1 on mushroom spines, as this was the only spine subtype in which density was significantly increased relative to vehicle (Fig. $3 B ; p=0.0013$ ). To determine whether G-1 might also potentiate spinogenesis in behaviorally trained mice, we then examined effects of DH G-1 infusion on spine density $40 \mathrm{~min}$ after completion of object training and G-1 infusion. The main effect of treatment was significant $\left(t_{(21)}=2.402, p=0.0256\right.$; Fig. $3 C$ ), suggesting that post-training G-1 infusion significantly increased total CA1 apical spine density. Again, we then recounted the same dendritic segments to assess effects on spine subtypes. Although raw values were a bit lower than those in Figure $3 A, B$, likely due to slight differences in batch and experimenter, the pattern of data was the same. A two-way ANOVA (spine type $\times$ treatment; Fig. $3 D$ ) revealed significant main effects of treatment $\left(F_{(1,103)}=9.958, p=0.0021\right)$ and spine type $\left(F_{(4,103)}=1278, p<\right.$ $0.0001)$, without a significant interaction $\left(F_{(4,103)}=1.998, p=\right.$ 0.1003 ). As was the case with behaviorally naive mice (Fig. $3 B$ ), only total spine number (Fig. $3 D ; p=0.0007$ ) and mushroom spine number (Fig. 3D; $p=0.0248$ ) were significantly increased by G-1. Because mushroom spines are considered mature (Tada and Sheng, 2006; Rochefort and Konnerth, 2012), these data suggest that G-1 selectively increases the density of mature spines on apical CA1 pyramidal dendrites.

Next, we examined the effects of G-1 on cofilin phosphorylation. DH tissue was dissected for 5, 15, or 30 min after DH infusion of vehicle or G-1. The main effect of treatment was not significant $\left(F_{(3,16)}=2.552, p=0.0921\right.$; Fig. $\left.4 A\right)$, but a priori $t$ tests relative to vehicle indicated a significant increase in cofilin phosphorylation following G-1 treatment relative to vehicle 5 and 15 min after infusion $\left(5 \mathrm{~min}, t_{(8)}=3.818, p=0.0051 ; 15 \mathrm{~min}, t_{(8)}=\right.$ 2.311, $p=0.0496$; Figure 4A). After Bonferroni correction for multiple comparisons, the difference at 5 min remained significant. Phospho-cofilin levels returned to baseline 30 min after G-1 infusion. These data suggested that GPER may affect hippocampal dendritic spine density via cofilin signaling.

To confirm that the G-1-induced phosphorylation of cofilin occurs via GPER activation, we coinfused G-1 with G-15, a selective GPER antagonist. To ensure that any effects of combined treatment were not simply due to a G-15-induced memory impairment, we used a dose of G-15 that we previously showed does not affect memory consolidation (Kim et al., 2016). DH tissue was collected $5 \mathrm{~min}$ after infusion due to robust effects at this time point (Fig. $4 A)$. The significant main effect of treatment $\left(F_{(2,14)}=\right.$ $13.83, p=0.005$; Fig. $4 B$ ) was driven by the G-1-induced increase in cofilin phosphorylation; phospho-cofilin levels were significantly higher than vehicle in the group receiving G-1 $(p=$ $0.0002)$, but not G-1 + G-15 ( $p=0.1639)$. The G-1 group also 
A CA1 Apical spine density
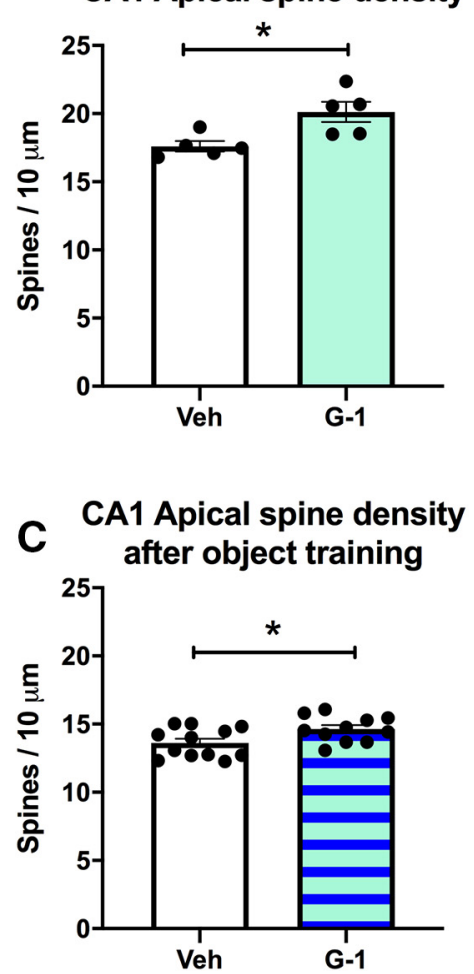

B

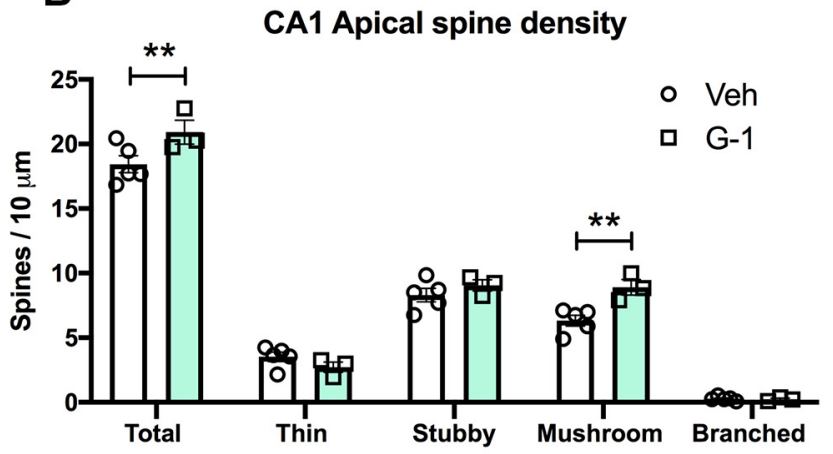

D

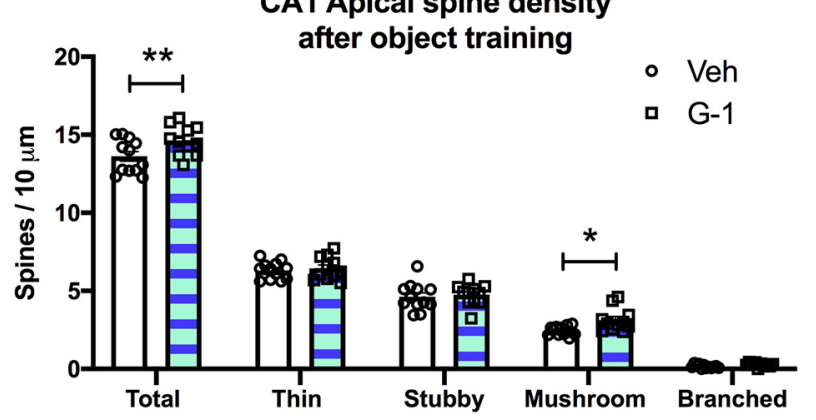

Figure 3. G-1 infusion induced spine density alterations. $A$, DH infusion of $4 \mathrm{ng} /$ hemisphere $\mathrm{G}-1$ into the $\mathrm{DH}$ increased apical CA1 spine density relative to vehicle 40 min later. $\boldsymbol{B}$, Reanalysis of the dendritic segments from $\boldsymbol{A}$ revealed that $\mathrm{G}-1$ not only increased total apical spine density, but also significantly increased mushroom-type spines relative to vehicle (Veh). $C$, Consistent with $\boldsymbol{A}$, $\mathrm{G}-1$ infusion ( $4 \mathrm{ng} /$ hemisphere) administered immediately after object training significantly increased apical CA1 spine density relative to vehicle 40 min later. D, Similar to behaviorally naive mice, $G-1$ infusion in object-trained mice significantly increased mushroom-type spines relative to vehicle. Error bars indicate mean \pm SEM. ${ }^{*} p<0.05$; ${ }^{* *} p<0.01$; relative to vehicle control.

exhibited significantly higher levels than the G-1 + G-15 group ( $p=0.0022$ ), indicating that G-15 blocked the effects of G-1. To determine the importance of JNK signaling in GPER-mediated cofilin phosphorylation, we coinfused G-1 with a behaviorally subeffective dose of the selective JNK inhibitor SP600125 (Kim et al., 2016). Again, G-1 infusion increased DH cofilin phosphorylation, and DH infusion of SP600125 blocked these effects $\left(F_{(2,19)}=5.031, p=0.0148\right.$; Fig. $\left.4 C\right)$. The G-1 group exhibited significantly higher phospho-cofilin levels than the vehicle $(p=$ $0.0057)$ and G-1 + SP600125 $(p=0.0261)$ groups, who did not differ from each other $(p=0.539)$.

We next investigated the importance of GPER activation and JNK signaling in G-1-mediated dendritic spine density alterations. The main effect of treatment was significant $\left(F_{(3,39)}=6.680, p=\right.$ 0.001; Fig. $4 D$ ), again due to the spinogenic effects of $G-1$. The vehicle, G-1 + G-15, and G-1 + SP600125 groups did not differ significantly from each other. In contrast, G-1 significantly increased CA1 apical spine density relative to the vehicle $(p=$ $0.0001), \mathrm{G}-1+\mathrm{G}-15$ ( $p=0.008)$, and G-1 + SP600125 $(p=$ 0.007 ) groups (Fig. $4 D$ ), suggesting that G-1-induced spine density changes are dependent on GPER activation and JNK signaling. These findings are consistent with our previous work showing an essential role for GPER activation and JNK signaling in G-1-mediated hippocampal memory consolidation (Kim et al., 2016). Collectively, the data from this series of experiments suggest that GPER activation regulates CA1 dendritic spine density and memory consolidation via JNK- and cofilin-regulated alterations in actin polymerization.
GPER activation is not required for $\mathrm{E}_{2}$-induced cofilin phosphorylation

Little is known about mechanisms underlying $\mathrm{E}_{2}$ - or estrogen receptor-induced changes in actin polymerization in vivo. Although it has been suggested that $\operatorname{ER} \alpha$ and $\operatorname{ER} \beta$ play a role in cofilin-related actin polymerization signaling (Briz and Baudry, 2014), a potential role for GPER activation in $\mathrm{E}_{2}$-mediated cofilin-actin polymerization signaling has not yet been examined. Because we have previously demonstrated that $\mathrm{E}_{2}$-mediated hippocampal memory consolidation is independent of GPER (Kim et al., 2016), we examined both the effects of $\mathrm{DH} \mathrm{E}_{2}$ infusion on cofilin phosphorylation and whether GPER activation is required for $\mathrm{E}_{2}$-mediated cofilin signaling alterations in the DH. OVXed mice received bilateral $\mathrm{DH}$ infusions of vehicle or $\mathrm{E}_{2}(5 \mu \mathrm{g} / \mathrm{hemi}$ sphere), and then DH tissue was dissected for Western blotting 5 , 15 , or 30 min later. The main effect of treatment was not significant $\left(F_{(3,20)}=2.149, p=0.1259\right.$; Fig. $\left.5 A\right)$, but an a priori Bonferroni-corrected $t$ test revealed that $\mathrm{E}_{2}$ infusion increased cofilin phosphorylation relative to vehicle 5 min after infusion $\left(t_{(10)}=3.148, p=0.0104\right)$. Phospho-cofilin levels were not significantly different from vehicle $15(p=0.0764)$ and $30(p=$ $0.3846)$ min after $E_{2}$ infusion. These data suggest that $E_{2}$ rapidly and transiently increases cofilin signaling in the $\mathrm{DH}$.

To examine a role for of GPER activation in $\mathrm{E}_{2}$-induced phosphorylation of cofilin, we coinfused $\mathrm{E}_{2}$ with $\mathrm{G}-15$. The main effect of treatment was significant $\left(F_{(2,17)}=4.499, p=0.027\right.$; Fig. $\left.5 B\right)$, with $E_{2}$ increasing cofilin phosphorylation relative to vehicle $(p=0.05)$. However, G-15 did not block this effect, as the $\mathrm{E}_{2}+$ G-15 group had significantly higher levels than the vehicle ( $p=$ 

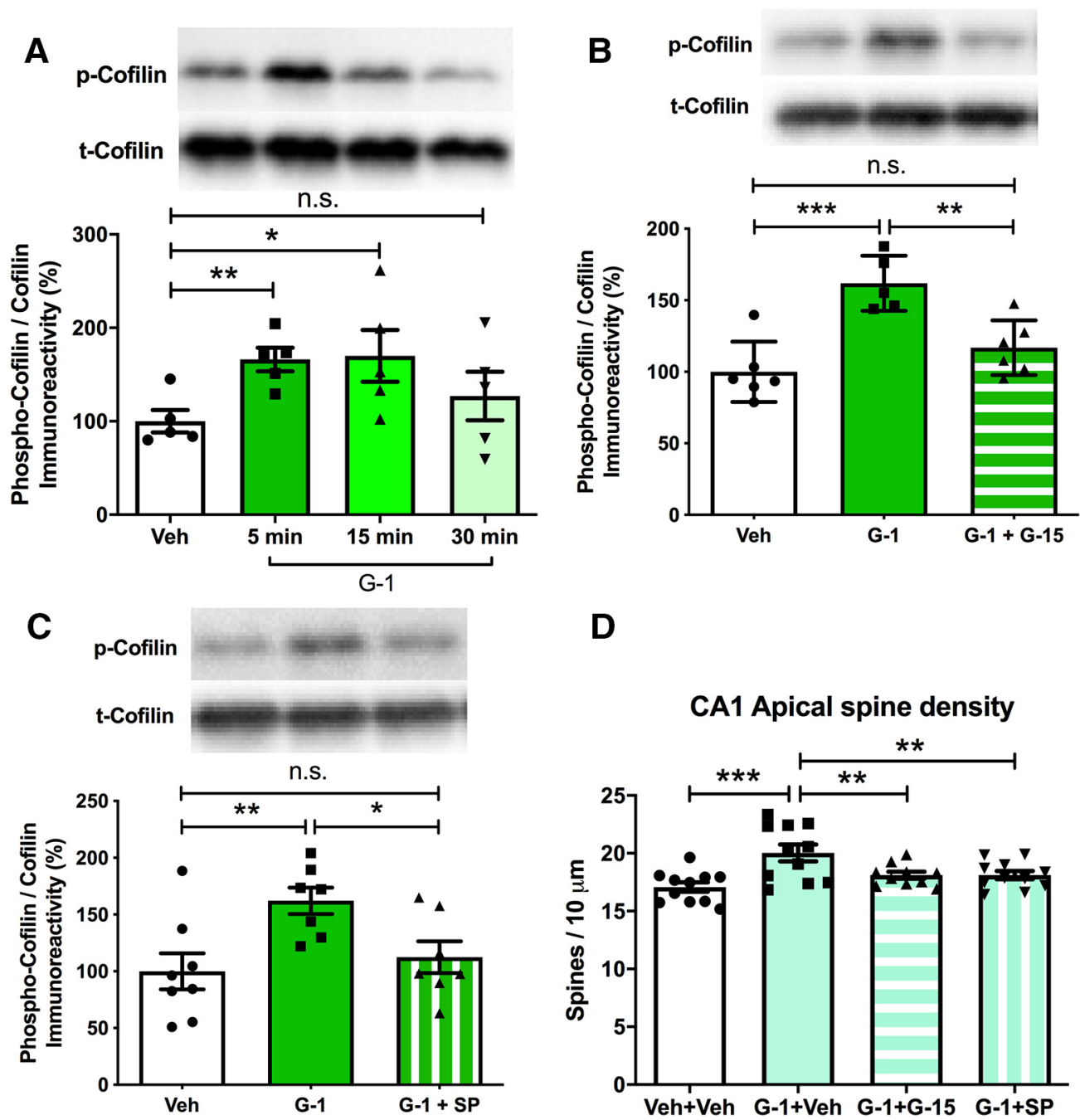

Figure 4. G-1-induced cofilin phosphorylation and spine density changes are dependent on GPER activation and JNK signaling. $A, G-1$ ( $4 \mathrm{ng} /$ hemisphere) infusion increased DH cofilin phosphorylation relative to vehicle (Veh) 5 and 15 min after DH infusion. $\boldsymbol{B}$, ICV infusion of $8 \mathrm{ng} \mathrm{G}-1$ significantly increased levels of phospho-cofilin 5 min later. These effects were blocked by DH infusion of the GPER antagonist G-15 (1.85 ng/hemisphere). C, The G-1-induced increase in phospho-cofilin was also blocked by DH infusion of SP600125 (SP; $2.75 \mathrm{ng} / \mathrm{hemisphere).} \mathrm{D,} \mathrm{ICV} \mathrm{infusion} \mathrm{of} 8 \mathrm{ng}$ G-1 significantly increased apical CA1 spine density relative to vehicle $40 \mathrm{~min}$ after infusion. DH infusion of either G-15 (1.85 ng/hemisphere) or SP ( $2.75 \mathrm{ng} / \mathrm{hemisphere)} \mathrm{blocked} \mathrm{this} \mathrm{increase.} \mathrm{Insets,}$ Representative Western blots. Error bars indicate mean \pm SEM. ${ }^{*} p<0.05 ;{ }^{* *} p<0.01 ;{ }^{* *} p<0.001$; relative to vehicle control or G-1-treated group. n.s. $=$ not significant.
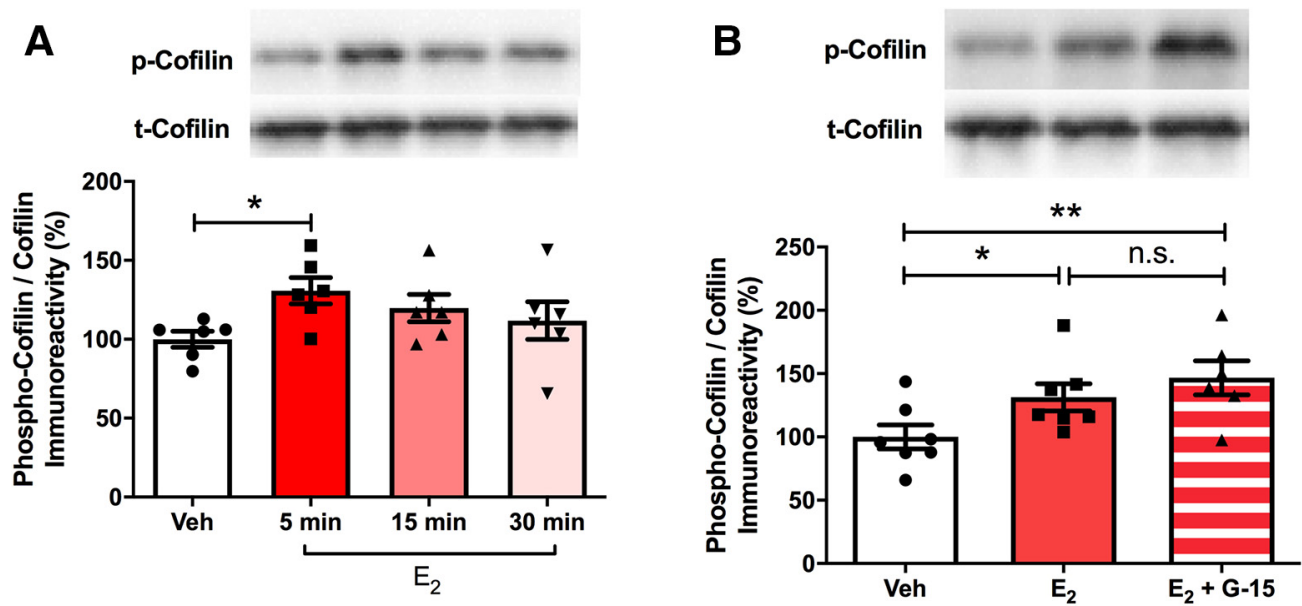

Figure 5. $E_{2}$-induced cofilin phosphorylation is not dependent on GPER activation. $A, E_{2}(5 \mu$ g/hemisphere) increased DH cofilin phosphorylation relative to vehicle (Veh) 5 min after DH infusion. $B$, ICV infusion of $10 \mu \mathrm{g} E_{2}$ significantly increased levels of phospho-cofilin in the DH. These effects were not blocked by DH infusion of G-15 (1.85 $\mathrm{ng} /$ hemisphere). Insets, Representative Western blots. Error bars indicate mean \pm SEM. ${ }^{*} p<0.05 ;{ }^{* *} p<0.01$; relative to vehicle control. 
A
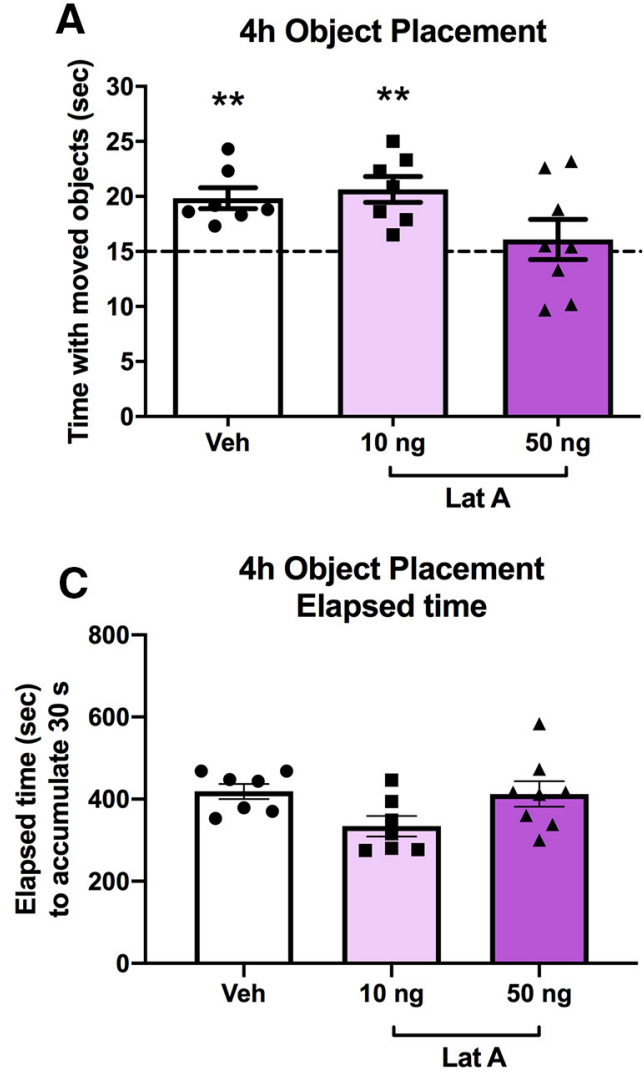

B

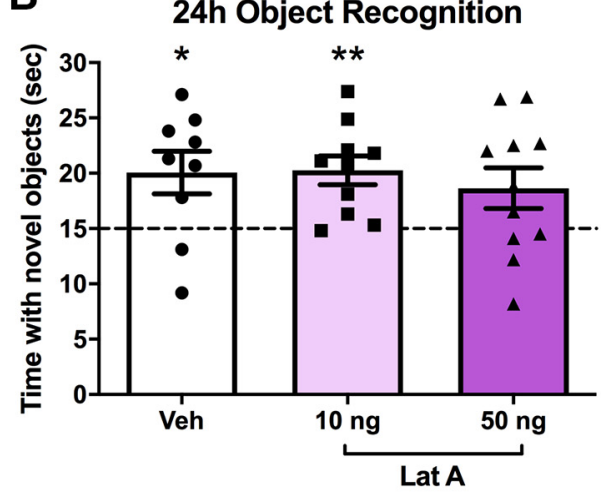

D 24h Object Recognition

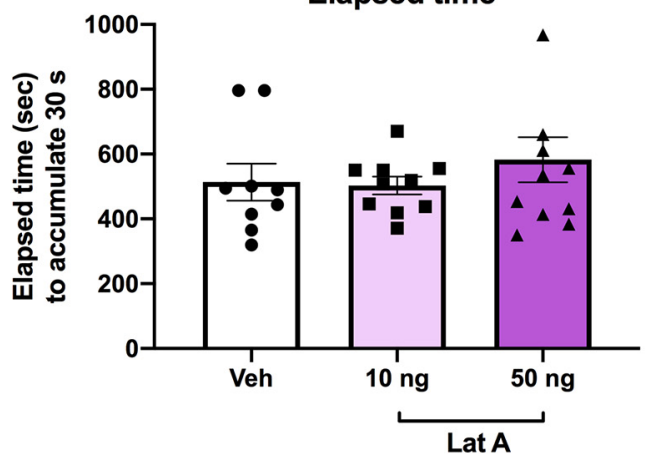

Figure 6. Actin polymerization inhibition alone impaired hippocampal memory consolidation. $\boldsymbol{A}$, Mice receiving DH infusion of vehicle (Veh) or $10 \mathrm{ng} /$ hemisphere latrunculin $\mathrm{A}$ (Lat A) spent significantly more time than chance (dashed line at $15 \mathrm{~s}$ ) with the moved object, demonstrating intact spatial memory consolidation. In contrast, mice receiving 50 ng/hemisphere Lat A spent no more time than chance with the moved object, indicating impaired spatial memory consolidation. B, Similarly, the Veh and 10 ng Lat A group, but not the 50 ng Lat A group, exhibited intact object recognition memory consolidation. These data indicate a critical role for actin polymerization in hippocampal memory consolidation, and reveal a behaviorally subeffective dose of Lat $A$ (10 ng/hemisphere) that could be used to probe the necessity of actin polymerization in $\mathrm{G}$-1-induced memory enhancement. ${ }^{*} p<0.05$; ${ }^{* *} p<0.01$; relative to chance level of $15 \mathrm{~s}$. $\boldsymbol{C}, \boldsymbol{D}$, Elapsed time to accumulate $30 \mathrm{~s}$ of exploration in OR and OP was not affected by Lat A infusion. Error bars indicate mean \pm SEM.

$0.010)$, but not $\mathrm{E}_{2}(p=0.351)$, group. These results suggest that $\mathrm{E}_{2}$-induced cofilin phosphorylation is not dependent on GPER activation, and are consistent with our previous work showing that the effects of $\mathrm{DH} \mathrm{E}_{2}$ infusion on object recognition and spatial memory consolidation in OVXed mice do not depend on GPER activation (Kim et al., 2016).

GPER-mediated spine density alterations and memory enhancement are dependent on actin polymerization in the hippocampus

We next used latrunculin A to determine whether actin polymerization is involved in the memory-enhancing effects of G-1. We first tested the effects of latrunculin A alone on memory consolidation in the OR and OP tasks. Four hours after OP training, mice infused with vehicle or $10 \mathrm{ng}$, but not $50 \mathrm{ng}$, latrunculin A, spent significantly more time with the moved object than chance (vehicle, $t_{(6)}=5.090, p=0.0022 ; 10 \mathrm{ng}, t_{(6)}=4.814, p=0.003 ; 50$ $\mathrm{ng}, t_{(7)}=0.5993, p=0.5679$; Figure $\left.6 A\right)$, suggesting that $50 \mathrm{ng}$ impaired spatial memory, whereas $10 \mathrm{ng}$ did not. Elapsed time to accumulate $30 \mathrm{~s}$ of exploration did not differ among the groups $\left(F_{(2,19)}=3.179, p=0.0644\right.$; Fig. $\left.6 C\right)$, suggesting no effect of latrunculin A on motivation to explore the objects. Similarly, $24 \mathrm{~h}$ after OR training, mice infused with vehicle or $10 \mathrm{ng}$, but not 50 ng, latrunculin A, spent significantly more time with the novel object than chance (vehicle, $t_{(8)}=2.631, p=0.0301 ; 10 \mathrm{ng}, t_{(9)}=$ 4.021, $p=0.003$; $50 \mathrm{ng}, t_{(10)}=1.991, p=0.074$; Figure $6 B$ ), indicating impaired object recognition memory after treatment with $50 \mathrm{ng}$, but not $10 \mathrm{ng}$, latrunculin A. Again, elapsed time did not differ among the OR groups $\left(F_{(2,27)}=0.6382, p=0.5360\right.$; Fig. 6D). However, one-way ANOVAs conducted on time spent with the novel/moved objects were not significant for OP $\left(F_{(2,19)}=\right.$ $3.052, p=0.0709)$ or $\mathrm{OR}\left(F_{(2,27)}=0.2793, p=0.7585\right)$, suggesting that both doses were generally too low to potently impair memory consolidation. Given that mice infused with $50 \mathrm{ng} /$ hemisphere did not remember object location in OP and tended to exhibit worse object identity memory in OR, a higher dose is likely to more strongly impair memory consolidation in these two tasks. Nevertheless, these experiments allowed us to determine that 10 $\mathrm{ng} /$ hemisphere latrunculin A had no effect on memory consolidation on its own, thereby allowing us to coinfuse this dose with G-1 in the next series of studies in which mice were infused with vehicle, G-1, or G-1 + latrunculin A.

In our first study, there was a significant main effect of treatment on CA1 apical spine density $\left(F_{(2,26)}=25.67, p<0.0001\right.$; Fig. $7 A)$, such that $\mathrm{G}-1$ increased spine density relative to the vehicle $(p<0.0001)$ and G-1 + latrunculin A $(p=0.0001$; Fig. $7 A)$ groups, who did not differ from each other $(p=0.9119)$. Finally, we investigated a role for actin polymerization in GPERmediated hippocampal memory enhancement. In both tasks, latrunculin A blocked the memory-enhancing effects of G-1 (Fig. $7 B, C)$. Mice receiving G-1 + vehicle showed a significant preference for the moved object $\left(t_{(11)}=3.987, p=0.0021\right)$ or novel object $\left(t_{(9)}=8.073, p=0.0001\right)$, whereas mice receiving vehicle (moved object, $t_{(10)}=0.9013, p=0.3886$; novel object, $t_{(10)}=$ 
A CA1 Apical spine density
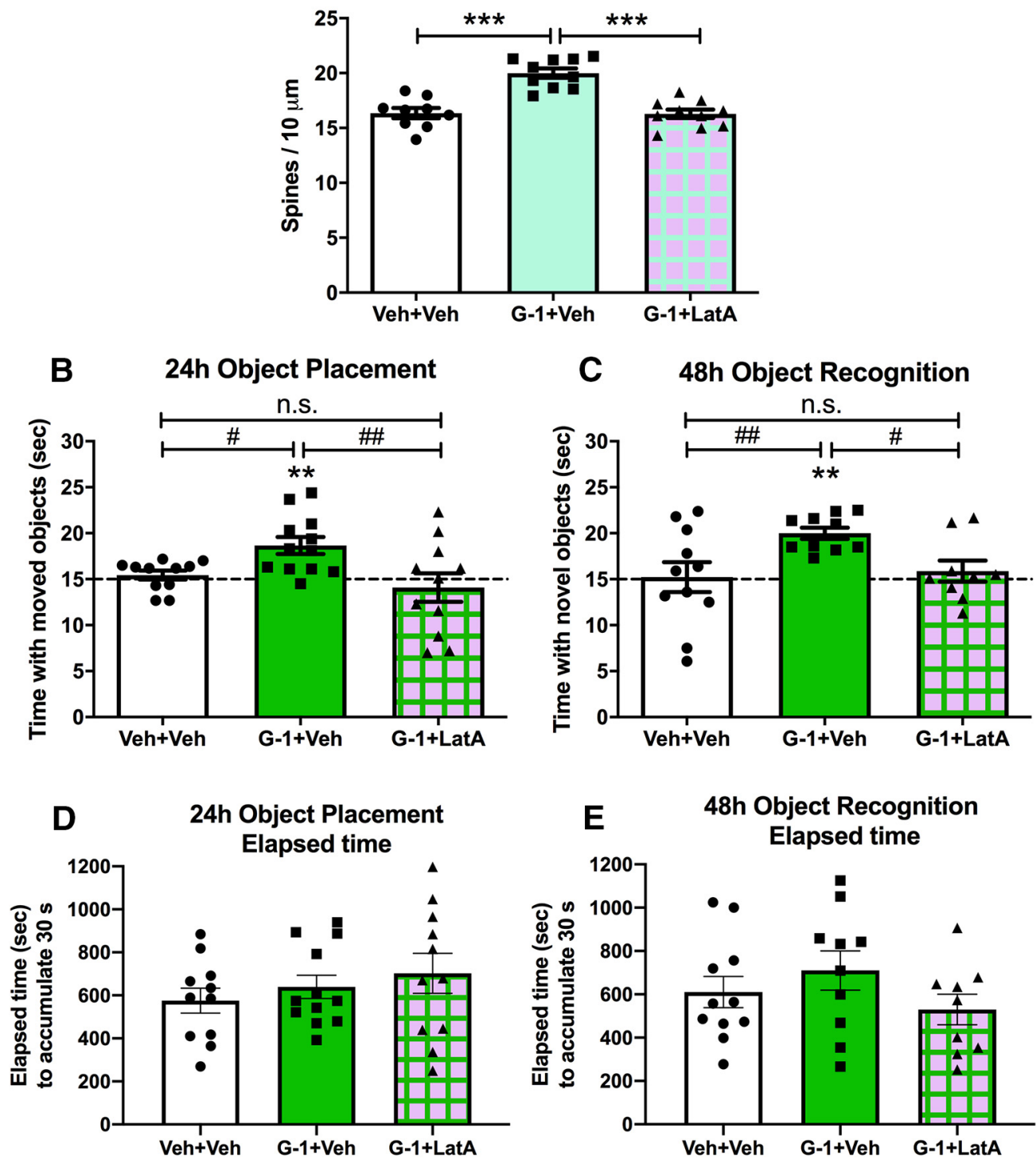

Figure 7. GPER-mediated memory enhancement and spine density alteration are dependent on hippocampal actin rearrangement. $\boldsymbol{A}, \mathrm{I}$ ICV infusion of $8 \mathrm{ng}$ G-1 significantly increased apical spine density, and DH infusion of the behaviorally subeffective $10 \mathrm{ng} /$ hemisphere latrunculin $\mathrm{A}$ (Lat A) blocked this effect. ${ }^{* * *} p<0.01$, relative to vehicle or G-1-treated group. $\boldsymbol{B}$, Consistent with the spine data, ICV infusion of G-1 significantly enhanced spatial memory relative to Veh and chance, and DH infusion of Lat A abolished this effect. C, Similarly, Lat A prevented G-1 from enhancing object recognition memory consolidation relative to Veh and chance. ${ }^{* *} p<0.01$, relative to chance. ${ }^{\#} p<0.05$; ${ }^{\# \#} p<0.01$; relative to the Veh or G-1-treated group. $\boldsymbol{D}, \boldsymbol{E}$, In both the $0 \mathrm{P}$ and $0 \mathrm{R}$ tasks, elapsed time to accumulate $30 \mathrm{~s}$ of exploration was not affected by either dose of Lat A. Error bars indicate mean \pm SEM. n.s. $=$ not significant.

0.1463, $p=0.8866$ ) or G-1 + latrunculin A did not (moved object, $t_{(10)}=0.5915, p=0.5673$; novel object, $t_{(8)}=0.7686, p=$ 0.4642 ), suggesting that actin polymerization is essential for G-1 to enhance memory. These findings were supported by significant main effects of treatment for both tasks $\left(\mathrm{OP}, F_{(2,31)}=4.935\right.$, $\left.p=0.0138 ; \mathrm{OR}, F_{(2,27)}=4.371, p=0.0227\right)$ and post hoc analyses showing that the G-1 + vehicle group spent significantly more time with the moved and novel objects than the vehicle $(\mathrm{OP}, p=$ 0.041; OR, $p=0.01)$ and $\mathrm{G}-1$ + latrunculin A (OP, $p=0.005$; $\mathrm{OR}, p=0.031)$ groups, who did not differ from each other (OP, $p=0.3823$; OR, $p=0.715)$. Elapsed time to accumulate $30 \mathrm{~s}$ of exploration did not differ among the groups for either $\mathrm{OP}\left(F_{(2,31)}=\right.$ $0.8064, p=0.4556$; Fig. $7 D)$ or $\mathrm{OR}\left(F_{(2,27)}=1.261, p=0.2995\right.$; Fig. $7 E)$. Together, these results suggest that GPER-mediated object recognition and spatial memory enhancement are dependent on actin polymerization in the hippocampus.

\section{Discussion}

The present findings suggest that actin polymerization plays a pivotal role in GPER-mediated memory enhancement and CA1 dendritic spine remodeling. Here, we used phosphorylation of the actin-binding protein cofilin as a proxy for actin regulation because cofilin is a critical regulator of actin dynamics, and kinase-induced inactivation of cofilin via phosphorylation is necessary for spinogenesis and LTP maintenance (Chen et al., 2007; Kramár et al., 2009). The results provide the first evidence that GPER enhances hippocampal memory consolidation and regulates dendritic spine density in females by modulating actin dynamics via JNK and cofilin signaling (Fig. 8).

We first examined whether object training could increase CA1 dendritic spine density within $40 \mathrm{~min}$. Although an earlier time point than in previous studies (Moser et al., 1994; Knafo et al., 


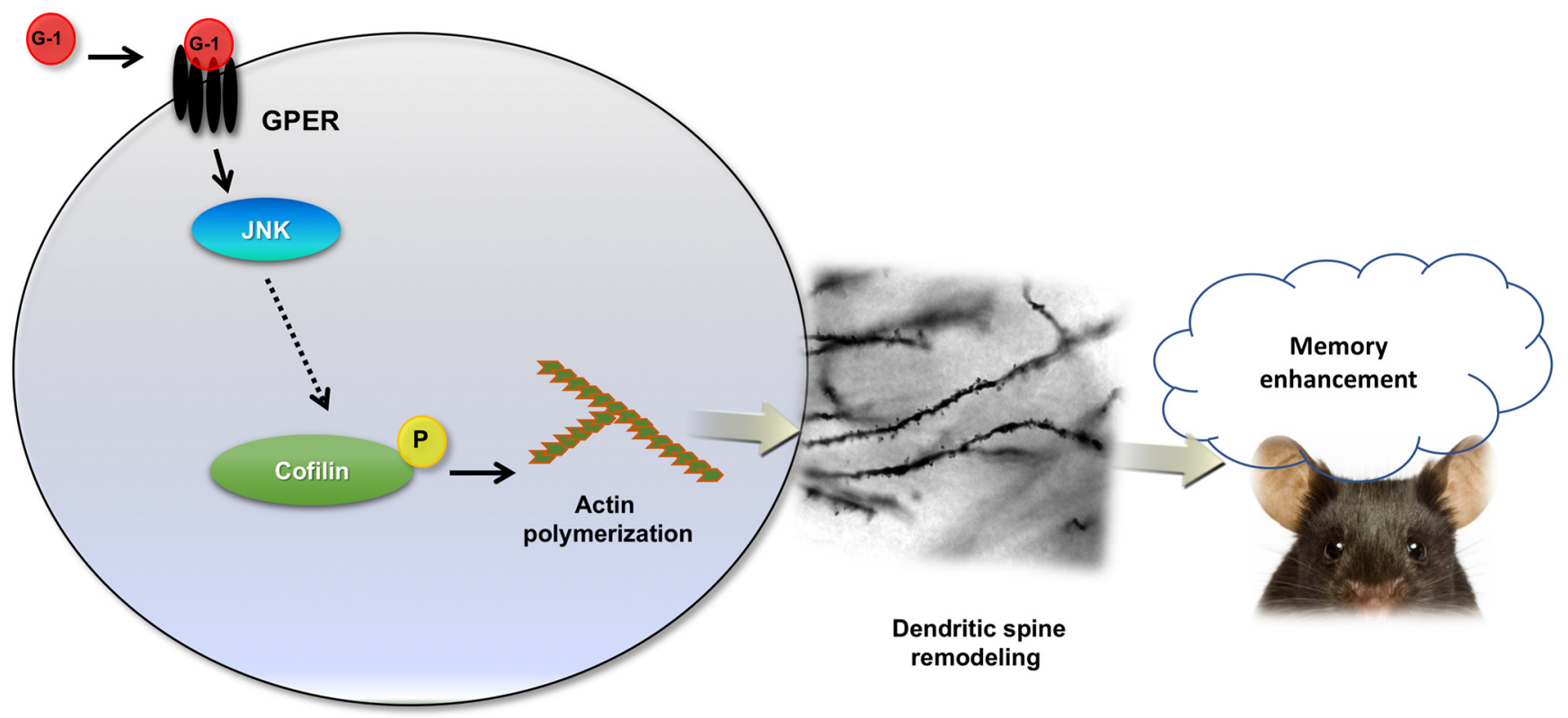

Figure 8. Proposed mechanisms involved in the role of actin polymerization in GPER-mediated hippocampal memory enhancement and spinogenesis in female mice. Hippocampal actin polymerization plays a vital role in GPER-mediated hippocampal spine density alterations and memory consolidation. Also, GPER activation increases cofilin phosphorylation in a manner that depends on JNK activation.

2001; Lai et al., 2012), we expected rapid spine remodeling because canonical Wnt/ $\beta$-catenin signaling, a key pathway involved in hippocampal spinogenesis (Murase et al., 2002; Gogolla et al., 2009; Ciani et al., 2011), is triggered in the mouse hippocampus within 5-30 min of object training (Fortress et al., 2013a). Here, training increased CA1 spine density by $11.6 \%$ and $7.5 \%$ relative to home cage and yoked controls, respectively, similar to the increase observed in the piriform cortex following olfactory learning (Knafo et al., 2001). Although density in yoked controls was statistically intermediate between the home-cage and training groups, this is to be expected, as contextual learning in the empty arena surely drives some spinogenesis. The additional $7.5 \%$ spine increase induced by object exploration, though modest, appears sufficient to support consolidation of information about both object location and identity. Previous work suggests that learning-induced increases in synapse number are transient (O’Malley et al., 1998; Nimchinsky et al., 2002); for instance, a twofold increase in hippocampal dentate spine density evident $6 \mathrm{~h}$ after avoidance conditioning training had subsided by $72 \mathrm{~h}$ (O'Malley et al., 1998). Because we examined just a single time point, the duration of the object learning-induced increase in CA1 spine density is unknown. However, these data suggest that object learning increases CA1 dendritic spine density, which may be further augmented or maintained by $E_{2}$ or G-1. Support for a multistep plasticity process comes from work in cultured cortical neurons showing that $\mathrm{E}_{2}$-induced spinogenesis is maintained by subsequent NMDA receptor activation (Srivastava et al., 2008).

We previously demonstrated that G-1 mimicked the beneficial effects of $E_{2}$ on object recognition and spatial memory consolidation (Kim et al., 2016), and reported that $\mathrm{DH}$ infusion of $\mathrm{E}_{2}$ increases CA1 dendritic spine density in the DH (Tuscher et al., 2016). Here, we sought to determine whether GPER activation enhances memory consolidation by increasing CA1 dendritic spine density. DH G-1 infusion increased CA1 apical spine density within $40 \mathrm{~min}$, which is consistent with a previous report of increased CA1 dendritic spine density 40 min after systemic G-1 treatment (Gabor et al., 2015). The timing of G-1's effects is consistent with those of $\mathrm{E}_{2}$, as $\mathrm{E}_{2}$ administered systemically or into the DH increases DH CA1 dendritic spine density $30 \mathrm{~min}$ and $2 \mathrm{~h}$ later (MacLusky et al., 2005; Inagaki et al., 2012; Tuscher et al., 2016; Avila et al., 2017). Moreover, the rapid effects of G-1 and $\mathrm{E}_{2}$ on $\mathrm{CA} 1$ spine morphology are consistent as well, given the selective increase in mushroom spines produced by G- 1 within 40 min (this study) and $\mathrm{E}_{2}$ within 120 min (Avila et al., 2017). Interestingly, the effects were seen in both behaviorally naive and behaviorally trained mice. Together, these data indicate that both $\mathrm{E}_{2}$ and GPER activation rapidly and selectively increase the density of mature spines in the dorsal hippocampal CA1.

Because we previously reported that G-1 rapidly phosphorylated both isoforms of the JNK in the DH (Kim et al., 2016), we also examined the role of JNK in GPER-mediated spinogenesis and cofilin phosphorylation. Interactions between GPER and PSD-95 have been identified in hippocampal dendritic spines (Akama et al., 2013), and JNK activity regulates PSD-95 to recruit synaptic AMPA receptors (Kim et al., 2007). Because the distribution of functional AMPA receptors is tightly correlated with dendritic spine geometry in CA1 pyramidal neurons (Matsuzaki et al., 2001), JNK signaling is likely important for synaptic transmission. We previously used the selective JNK inhibitor SP600125 to demonstrate an essential role for JNK signaling in G-1-mediated hippocampal memory consolidation in OVXed mice (Kim et al., 2016). The present data indicate that JNK signaling is also important for G-1-induced cofilin phosphorylation and CA1 dendritic spinogenesis. However, little is known about the role of JNK in mediating cofilin signaling, and data from various tissues are inconsistent. For example, JNK inhibition decreased phosphocofilin levels in vascular endothelial cells (Slee and Lowe-Krentz, 2013), and JNK activation at axon tips in hippocampal neuron cultures facilitates axon elongation by increasing cofilin phosphorylation and promoting actin polymerization (Sun et al., 2013). Although these results suggest that JNK can enhance cofilin phosphorylation, other data indicate that JNK promotes dephosphorylation of cofilin in rat aortic smooth muscle cells (Won et al., 2008). The present findings are the first to indicate that JNK 
mediates the effects of hormonal modulators on cofilin phosphorylation in the brain, which suggests an important link between JNK and cofilin that is ripe for further study.

Although $\mathrm{E}_{2}$ and other estrogenic compounds bind GPER with a high affinity in human cell lines (Funakoshi et al., 2006; Thomas and Dong, 2006), some investigators believe that GPER functions more as a collaborator in mediating the biological actions of estrogens rather than as a true estrogen receptor, such as $\mathrm{ER} \alpha$ and $\mathrm{ER} \beta$ (Levin, 2009; Langer et al., 2010). This notion is consistent with our previous work showing that GPER and $\mathrm{E}_{2}$ act independently in the OVXed mouse DH to mediate OR and OP memory consolidation (Kim et al., 2016). This report showed that G-1 enhanced memory via JNK phosphorylation, whereas $E_{2}$ did so via ERK activation, and that $\mathrm{G}-15$ did not prevent $\mathrm{E}_{2}$ from enhancing memory (Kim et al., 2016). Similarly, G-15 in the present study did not prevent $\mathrm{E}_{2}$ from increasing $\mathrm{DH}$ cofilin phosphorylation, indicating that GPER activation is also not required for $\mathrm{E}_{2}$ to regulate cofilin activation. This finding is supported by other studies showing that $\mathrm{E}_{2}$ and GPER may affect spines independently (Pedram et al., 2006; Madak-Erdogan et al., 2008; Otto et al., 2008; Briz and Baudry, 2014; Ding et al., 2015). Of the two canonical estrogen receptors, $E_{2}$ appears to rapidly regulate CA1 dendritic spines via activation of $\mathrm{ER} \alpha$, but not $\mathrm{ER} \beta$ (Phan et al., 2011, 2015), suggesting that $E_{2}$ effects on spine remodeling may involve activation of $\mathrm{ER} \alpha$, but not $\mathrm{ER} \beta$ or GPER. In addition, we showed here that $\mathrm{E}_{2}$-induced cofilin phosphorylation was smaller and more transient than that mediated by G-1 (Cohen's $d$ of 1.816 for $\mathrm{E}_{2}$ vs 2.414 for $\mathrm{G}$-1). If $\mathrm{E}_{2}$ activates cofilin by binding to GPER, then it should have produced levels of cofilin phosphorylation at least comparable with G-1 infusion. Thus, these results support the conclusion that GPER regulates cofilinmediated actin polymerization independently of $\mathrm{E}_{2}$ in the $\mathrm{DH}$. However, we cannot yet exclude the possibility that other potential interactions between $E_{2}$ and GPER could be revealed with different drug doses or infusion timing.

Finally, to link the effects of GPER activation on cofilin and spine density with its beneficial effects on hippocampal memory consolidation, we assessed whether inhibiting actin polymerization could prevent GPER from enhancing memory. We established a dose of latrunculin A with no detrimental effects on memory consolidation to ensure that any impairment seen in combination with G-1 resulted from an interaction between the compounds rather than a general memory impairment induced by latrunculin A. DH infusion of the behaviorally subeffective dose of $10 \mathrm{ng} /$ hemisphere latrunculin A prevented G-1 from increasing CA1 dendritic spine density and blocked its memoryenhancing effects, suggesting a critical role for actin polymerization in G-1-induced spine density changes and hippocampal memory enhancement. These data provide the first evidence that actin rearrangement is essential for GPER-mediated hippocampal memory consolidation. Because identifying the downstream molecular mechanisms through which GPER affects memory may assist considering GPER as a new target for the development of memoryenhancing drugs, these data may provide promising new avenues for the development of novel therapies that mimic the memoryenhancing effects of estrogens without harmful side effects.

In conclusion, this study provides novel insights into the cellsignaling mechanisms through which GPER regulates hippocampal dendritic spine density and memory consolidation. This work also supports the conclusion that hippocampal GPER does not function like a canonical estrogen receptor to regulate memory consolidation in OVXed mice, despite mimicking the beneficial effects of $\mathrm{E}_{2}$ on spine remodeling and hippocampal memory con- solidation. As such, these studies may suggest first steps toward new therapeutics that safely and effectively reduce memory decline in menopausal women. Although hormone therapy can reduce the risk of menopause-related memory decline and dementia in women, current treatments are not recommended because of increased risks of cancer, heart disease, and stroke (Rossouw et al., 2002; Coker et al., 2010). Because GPER influences hippocampal morphology and memory consolidation via different molecular mechanisms than $\mathrm{E}_{2}$, this receptor could be a valuable target for future drug development.

\section{References}

Akama KT, Thompson LI, Milner TA, McEwen BS (2013) Post-synaptic density-95 (PSD-95) binding capacity of G-protein-coupled receptor 30 (GPR30), an estrogen receptor that can be identified in hippocampal dendritic spines. J Biol Chem 288:6438-6450.

Avila JA, Alliger AA, Carvajal B, Zanca RM, Serrano PA, Luine VN (2017) Estradiol rapidly increases GluA2-mushroom spines and decreases GluA2filopodia spines in hippocampus CA1. Hippocampus 27:1224-1229.

Babayan AH, Kramár EA (2013) Rapid effects of oestrogen on synaptic plasticity: interactions with actin and its signalling proteins. J Neuroendocrinol 25:1163-1172.

Blasko E, Haskell CA, Leung S, Gualtieri G, Halks-Miller M, Mahmoudi M, Dennis MK, Prossnitz ER, Karpus WJ, Horuk R (2009) Beneficial role of the GPR30 agonist G-1 in an animal model of multiple sclerosis. J Neuroimmunol 214:66-77.

Bologa CG, Revankar CM, Young SM, Edwards BS, Arterburn JB, Kiselyov AS, Parker MA, Tkachenko SE, Savchuck NP, Sklar LA, Oprea TI, Prossnitz ER (2006) Virtual and biomolecular screening converge on a selective agonist for GPR30. Nat Chem Biol 2:207-212.

Boulware MI, Heisler JD, Frick KM (2013) The memory-enhancing effects of hippocampal estrogen receptor activation involve metabotropic glutamate receptor signaling. J Neurosci 33:15184-15194.

Briz V, Baudry M (2014) Estrogen regulates protein synthesis and actin polymerization in hippocampal neurons through different molecular mechanisms. Front Endocrinol (Lausanne) 5:22.

Chen LY, Rex CS, Casale MS, Gall CM, Lynch G (2007) Changes in synaptic morphology accompany actin signaling during LTP. J Neurosci 27:53635372 .

Ciani L, Boyle KA, Dickins E, Sahores M, Anane D, Lopes DM, Gibb AJ, Salinas PC (2011) Wnt7a signaling promotes dendritic spine growth and synaptic strength through $\mathrm{Ca}(2)(+) /$ calmodulin-dependent protein kinase II. Proc Natl Acad Sci U S A 108:10732-10737.

Coker LH, Espeland MA, Rapp SR, Legault C, Resnick SM, Hogan P, Gaussoin S, Dailey M, Shumaker SA (2010) Postmenopausal hormone therapy and cognitive outcomes: the Women's health initiative memory study (WHIMS). J Steroid Biochem Mol Biol 118:304-310.

DeKosky ST, Scheff SW (1990) Synapse loss in frontal cortex biopsies in Alzheimer's disease: correlation with cognitive severity. Ann Neurol 27: 457-464.

Dennis MK, Burai R, Ramesh C, Petrie WK, Alcon SN, Nayak TK, Bologa CG, Leitao A, Brailoiu E, Deliu E, Dun NJ, Sklar LA, Hathaway HJ, Arterburn JB, Oprea TI, Prossnitz ER (2009) In vivo effects of a GPR30 antagonist. Nat Chem Biol 5:421-427.

Ding Q, Hussain Y, Chorazyczewski J, Gros R, Feldman RD (2015) GPERindependent effects of estrogen in rat aortic vascular endothelial cells. Mol Cell Endocrinol 399:60-68.

Fan L, Zhao Z, Orr PT, Chambers CH, Lewis MC, Frick KM (2010) Estradiol-induced object memory consolidation in middle-aged female mice requires dorsal hippocampal extracellular signal-regulated kinase and phosphatidylinositol 3-kinase activation. J Neurosci 30:4390-4400.

Fernandez SM, Lewis MC, Pechenino AS, Harburger LL, Orr PT, Gresack JE, Schafe GE, Frick KM (2008) Estradiol-induced enhancement of object memory consolidation involves hippocampal extracellular signal-regulated kinase activation and membrane-bound estrogen receptors. J Neurosci 28: $8660-8667$.

Fortress AM, Schram SL, Tuscher JJ, Frick KM (2013a) Canonical wnt signaling is necessary for object recognition memory consolidation. J Neurosci 33:12619-12626.

Fortress AM, Fan L, Orr PT, Zhao Z, Frick KM (2013b) Estradiol-induced 
object recognition memory consolidation is dependent on activation of mTOR signaling in the dorsal hippocampus. Learn Mem 20:147-155.

Fortress AM, Kim J, Poole RL, Gould TJ, Frick KM (2014) 17 $\beta$-estradiol regulates histone alterations associated with memory consolidation and increases BDNF promoter acetylation in middle-aged female mice. Learn Mem 21:457-467.

Frankfurt M, Salas-Ramirez K, Friedman E, Luine V (2011) Cocaine alters dendritic spine density in cortical and subcortical brain regions of the postpartum and virgin female rat. Synapse 65:955-961.

Funakoshi T, Yanai A, Shinoda K, Kawano MM, Mizukami Y (2006) G protein-coupled receptor 30 is an estrogen receptor in the plasma membrane. Biochem Biophys Res Commun 346:904-910.

Gabor C, Lymer J, Phan A, Choleris E (2015) Rapid effects of the G-protein coupled oestrogen receptor (GPER) on learning and dorsal hippocampus dendritic spines in female mice. Physiol Behav 149:53-60.

Gogolla N, Galimberti I, Deguchi Y, Caroni P (2009) Wnt signaling mediates experience-related regulation of synapse numbers and mossy fiber connectivities in the adult hippocampus. Neuron 62:510-525.

Hammond R, Gibbs RB (2011) GPR30 is positioned to mediate estrogen effects on basal forebrain cholinergic neurons and cognitive performance. Brain Res 1379:53-60.

Harris KM, Jensen FE, Tsao B (1992) Three-dimensional structure of dendritic spines and synapses in rat hippocampus (CA1) at postnatal day 15 and adult ages: implications for the maturation of synaptic physiology and long-term potentiation. J Neurosci 12:2685-2705.

Honkura N, Matsuzaki M, Noguchi J, Ellis-Davies GC, Kasai H (2008) The subspine organization of actin fibers regulates the structure and plasticity of dendritic spines. Neuron 57:719-729.

Inagaki T, Frankfurt M, Luine V (2012) Estrogen-induced memory enhancements are blocked by acute bisphenol $\mathrm{A}$ in adult female rats: role of dendritic spines. Endocrinology 153:3357-3367.

Kim J, Szinte JS, Boulware MI, Frick KM (2016) 17 $\beta$-Estradiol and agonism of G-protein-coupled estrogen receptor enhance hippocampal memory via different cell-signaling mechanisms. J Neurosci 36:3309-3321.

Kim MJ, Futai K, Jo J, Hayashi Y, Cho K, Sheng M (2007) Synaptic accumulation of PSD-95 and synaptic function regulated by phosphorylation of serine-295 of PSD-95. Neuron 56:488-502.

Knafo S, Grossman Y, Barkai E, Benshalom G (2001) Olfactory learning is associated with increased spine density along apical dendrites of pyramidal neurons in the rat piriform cortex. Eur J Neurosci 13:633-638.

Kramár EA, Chen LY, Brandon NJ, Rex CS, Liu F, Gall CM, Lynch G (2009) Cytoskeletal changes underlie estrogen's acute effects on synaptic transmission and plasticity. J Neurosci 29:12982-12993.

Lai CS, Franke TF, Gan WB (2012) Opposite effects of fear conditioning and extinction on dendritic spine remodelling. Nature 483:87-91.

Langer G, Bader B, Meoli L, Isensee J, Delbeck M, Noppinger PR, Otto C (2010) A critical review of fundamental controversies in the field of GPR30 research. Steroids 75:603-610.

Levin ER (2009) G protein-coupled receptor 30: estrogen receptor or collaborator? Endocrinology 150:1563-1565.

Lymer J, Robinson A, Winters BD, Choleris E (2017) Rapid effects of dorsal hippocampal G-protein coupled estrogen receptor on learning in female mice. Psychoneuroendocrinology 77:131-140.

MacLusky NJ, Luine VN, Hajszan T, Leranth C (2005) The $17 \alpha$ and $17 \beta$ isomers of estradiol both induce rapid spine synapse formation in the CA1 hippocampal subfield of ovariectomized female rats. Endocrinology 146:287-293.

Madak-Erdogan Z, Kieser KJ, Kim SH, Komm B, Katzenellenbogen JA, Katzenellenbogen BS (2008) Nuclear and extranuclear pathway inputs in the regulation of global gene expression by estrogen receptors. Mol Endocrinol 22:2116-2127.

Matsuzaki M, Ellis-Davies GC, Nemoto T, Miyashita Y, Iino M, Kasai H (2001) Dendritic spine geometry is critical for AMPA receptor expression in hippocampal CA1 pyramidal neurons. Nat Neurosci 4:1086-1092.

McClure RE, Barha CK, Galea LA (2013) $17 \beta$-Estradiol, but not estrone, increases the survival and activation of new neurons in the hippocampus in response to spatial memory in adult female rats. Horm Behav 63:144157.

Moser MB, Trommald M, Andersen P (1994) An increase in dendritic spine density on hippocampal CA1 pyramidal cells following spatial learning in adult rats suggests the formation of new synapses. Proc Natl Acad Sci U S A 91:12673-12675.
Mukai H, Tsurugizawa T, Murakami G, Kominami S, Ishii H, Ogiue-Ikeda M, Takata N, Tanabe N, Furukawa A, Hojo Y, Ooishi Y, Morrison JH, Janssen WG, Rose JA, Chambon P, Kato S, Izumi S, Yamazaki T, Kimoto T, Kawato S (2007) Rapid modulation of long-term depression and spinogenesis via synaptic estrogen receptors in hippocampal principal neurons. J Neurochem 100:950-967.

Murase S, Mosser E, Schuman EM (2002) Depolarization drives betacatenin into neuronal spines promoting changes in synaptic structure and function. Neuron 35:91-105.

Nelson BS, Witty CF, Williamson EA, Daniel JM (2012) A role for hippocampal actin rearrangement in object placement memory in female rats. Neurobiol Learn Mem 98:284-290.

Nimchinsky EA, Sabatini BL, Svoboda K (2002) Structure and function of dendritic spines. Annu Rev Physiol 64:313-353.

O’Malley A, O'Connell C, Regan CM (1998) Ultrastructural analysis reveals avoidance conditioning to induce a transient increase in hippocampal dentate spine density in the 6 hour post-training period of consolidation. Neuroscience 87:607-613.

Otto C, Rohde-Schulz B, Schwarz G, Fuchs I, Klewer M, Brittain D, Langer G, Bader B, Prelle K, Nubbemeyer R, Fritzemeier KH (2008) G proteincoupled receptor 30 localizes to the endoplasmic reticulum and is not activated by estradiol. Endocrinology 149:4846-4856.

Paletta P, Sheppard PA, Matta R, Ervin KS, Choleris E (2018) Rapid effects of estrogens on short-term memory: possible mechanisms. Horm Behav 104:88-99.

Pedram A, Razandi M, Levin ER (2006) Nature of functional estrogen receptors at the plasma membrane. Mol Endocrinol 20:1996-2009.

Penzes P, Cahill ME (2012) Deconstructing signal transduction pathways that regulate the actin cytoskeleton in dendritic spines. Cytoskeleton (Hoboken) 69:426-441.

Phan A, Lancaster KE, Armstrong JN, MacLusky NJ, Choleris E (2011) Rapid effects of estrogen receptor alpha and beta selective agonists on learning and dendritic spines in female mice. Endocrinology 152:14921502.

Phan A, Suschkov S, Molinaro L, Reynolds K, Lymer JM, Bailey CD, Kow LM, MacLusky NJ, Pfaff DW, Choleris E (2015) Rapid increases in immature synapses parallel estrogen-induced hippocampal learning enhancements. Proc Natl Acad Sci U S A 112:16018-16023.

Pitha J, Pitha J (1985) Amorphous water-soluble derivatives of cyclodextrins: nontoxic dissolution enhancing excipients. J Pharm Sci 74:987-990.

Pitha J, Harman SM, Michel ME (1986) Hydrophilic cyclodextrin derivatives enable effective oral administration of steroidal hormones. J Pharm Sci 75:165-167.

Rochefort NL, Konnerth A (2012) Dendritic spines: from structure to in vivo function. EMBO Rep 13:699-708.

Rossouw JE, Anderson GL, Prentice RL, LaCroix AZ, Kooperberg C, Stefanick ML, Jackson RD, Beresford SA, Howard BV, Johnson KC, Kotchen JM, Ockene J (2002) Risks and benefits of estrogen plus progestin in healthy postmenopausal women. JAMA 288:321-333.

Slee JB, Lowe-Krentz LJ (2013) Actin realignment and cofilin regulation are essential for barrier integrity during shear stress. J Cell Biochem 114:782795.

Srivastava DP, Woolfrey K, Jones KA, Shum CY, Lash LL, Swanson GT, Penzes P (2008) Rapid enhancement of two-step wiring plasticity by estrogen and NMDA receptor activity. Proc Natl Acad Sci U S A 105:1465014655.

Sun T, Yu N, Zhai LK, Li N, Zhang C, Zhou L, Huang Z, Jiang XY, Shen Y, Chen ZY (2013) c-jun NH2-terminal kinase (JNK)-interacting protein-3 (JIP3) regulates neuronal axon elongation in a kinesin- and JNK-dependent manner. J Biol Chem 288:14531-14543.

Tada T, Sheng M (2006) Molecular mechanisms of dendritic spine morphogenesis. Curr Opin Neurobiol 16:95-101.

Terry RD, Masliah E, Salmon DP, Butters N, DeTeresa R, Hill R, Hansen LA, Katzman R (1991) Physical basis of cognitive alterations in Alzheimer's disease: synapse loss is the major correlate of cognitive impairment. Ann Neurol 30:572-580.

Thomas P, Dong J (2006) Binding and activation of the seventransmembrane estrogen receptor GPR30 by environmental estrogens: a potential novel mechanism of endocrine disruption. J Steroid Biochem Mol Biol 102:175-179.

Tuscher JJ, Luine V, Frankfurt M, Frick KM (2016) Estradiol-mediated 
spine changes in the dorsal hippocampus and medial prefrontal cortex of ovariectomized female mice depend on ERK and mTOR activation in the dorsal hippocampus. J Neurosci 36:1483-1489.

Won KJ, Park SH, Park T, Lee CK, Lee HM, Choi WS, Kim SJ, Park PJ, Jang HK, Kim SH, Kim B (2008) Cofilin phosphorylation mediates proliferation in response to platelet-derived growth factor-BB in rat aortic smooth muscle cells. J Pharmacol Sci 108:372-379.

Woolley CS, McEwen BS (1992) Estradiol mediates fluctuation in hippocampal synapse density during the estrous cycle in the adult rat. J Neurosci 12:2549-2554.

Woolley CS, Gould E, Frankfurt M, McEwen BS (1990) Naturally occurring fluctuation in dendritic spine density on adult hippocampal pyramidal neurons. J Neurosci 10:4035-4039.
Yarmola EG, Somasundaram T, Boring TA, Spector I, Bubb MR (2000) Actin-latrunculin A structure and function. Differential modulation of actin-binding protein function by latrunculin A. J Biol Chem 275: $28120-28127$.

Young EJ, Aceti M, Griggs EM, Fuchs RA, Zigmond Z, Rumbaugh G, Miller CA (2014) Selective, retrieval-independent disruption of methamphetamineassociated memory by actin depolymerization. Biol Psychiatry 75:96104.

Yuen GS, McEwen BS, Akama KT (2011) LIM kinase mediates estrogen action on the actin depolymerization factor cofilin. Brain Res 1379:44-52.

Zhao Z, Fan L, Frick KM (2010) Epigenetic alterations regulate estradiolinduced enhancement of memory consolidation. Proc Natl Acad Sci U S A 107:5605-5610. 